\title{
Postruminal infusion of calcium gluconate increases milk fat production and alters fecal volatile fatty acid profile in lactating dairy cows
}

\author{
John Doelman, ${ }^{1 *}$ Leslie L. McKnight, ${ }^{1}$ Michelle Carson, ${ }^{1}$ Kelly Nichols, ${ }^{2}$ Douglas F. Waterman, ${ }^{1}$ \\ and John A. Metcalf ${ }^{1}$ \\ ${ }^{1}$ Trouw Nutrition Agresearch, Guelph, Ontario, Canada N1G 4T2 \\ ${ }^{2}$ Department of Animal Biosciences, University of Guelph, Guelph, Ontario, Canada N1G 2W1
}

\section{ABSTRACT}

Gluconic acid is a carboxylic acid naturally occurring in plants and honey. In nonruminant animals, gluconic acid has been shown to increase gastrointestinal butyrate concentrations and improve growth performance, but a ruminant application remains undescribed. This experiment examined the effects of postruminal calcium gluconate $(\mathrm{CaG})$ on milk production, fecal volatile fatty acid concentrations, and plasma metabolite concentrations in lactating dairy cows. Six rumen cannulated multiparous Holstein cows $(60 \pm 6 \mathrm{~d}$ in milk) were randomly assigned to 6 treatment sequences within a $6 \times 6$ Latin square design in which each experimental period consisted of $5 \mathrm{~d}$ of continuous postruminal infusion followed by a $2 \mathrm{~d}$ wash-out period. Test treatments included a negative control (CON; $0.90 \% \mathrm{NaCl}$ wt/vol), positive control (Na-butyrate, $135 \mathrm{~g} / \mathrm{d}$ ), and 4 doses of $\mathrm{CaG}(44,93,140$, and $187 \mathrm{~g} / \mathrm{d})$. Cows received a total mixed ration (31\% corn silage, $28 \%$ alfalfa silage, $5 \%$ hay, $36 \%$ concentrate) with dry matter intake fixed $(25.3 \pm 1.7 \mathrm{~kg} / \mathrm{d})$ throughout the experiment. On d 5 of each infusion period, samples of milk, feces, and blood were collected from each animal. Calcium gluconate treatments increased milk fat concentration, and a tendency was observed for increased milk fat yield and energy-corrected milk yield above levels achieved by CON, with maximal treatment responses of $4.43 \%$ (CON 3.81\%), $2.089 \mathrm{~kg} / \mathrm{d}(\mathrm{CON} 1.760 \mathrm{~kg} / \mathrm{d})$, and 51.8 $\mathrm{kg} / \mathrm{d}(\mathrm{CON} 47.1 \mathrm{~kg} / \mathrm{d})$, respectively. Concentrations of iso-butyric acid in feces were greater in cows infused with $\mathrm{CaG}(13.3 \mu \mathrm{mol} / \mathrm{g})$ treatments compared with CON $(9.7 \mu \mathrm{mol} / \mathrm{g})$. Arterial concentrations of glucose and nonesterified fatty acids were lower (glucose: $\mathrm{CaG}$ $2.98 \mathrm{mmol} / \mathrm{L}$, CON $3.29 \mathrm{mmol} / \mathrm{L}$ and nonesterified fatty acids: CaG $0.130 \mathrm{mmol} / \mathrm{L}$ vs. $0.148 \mathrm{mmol} / \mathrm{L}$ ) and $\beta$-hydroxybutyrate higher ( $\mathrm{CaG} 1.703$ vs. CON 0.812)

Received June 1, 2018.

Accepted November 5, 2018.

*Corresponding author: john.doelman@trouwnutrition.com in cows infused with $\mathrm{CaG}$ than $\mathrm{CON}$. Together, these results suggest that postruminal infusion of CaG may alter metabolic mechanisms to support a milk fat production response.

Key words: gluconic acid, gastrointestinal tract, milk production, butyrate

\section{INTRODUCTION}

Butyrate is a fermentation product produced by microbes in the rumen and hindgut of dairy cattle. In the rumen, butyrate is the preferred energy source and modulates cellular differentiation and proliferation of the rumen epithelium (Bergman, 1990; Penner et al., 2011). Butyrate plays a similar role in the gastrointestinal tract (GIT) of nonruminant animals (Bergman, 1990; reviewed by McNabney and Henagan, 2017); however, the functional role of butyrate in the hindgut of ruminants is not well established. Increasing butyrate delivery to the hindgut of ruminants remains difficult to evaluate experimentally, as butyrate absorbed across the rumen epithelium is rapidly converted to ketones (Huhtanen et al., 1993; Miettinen and Huhtanen, 1996). Postruminal infusion of sodium butyrate (NaB) into the abomasum has been recently evaluated in lactating dairy cows (Herrick et al., 2017, 2018). The authors observed decreased plasma glucose, increased plasma ketones, and greater concentrations of VFA in milk compared with a saline control. These findings suggest that postruminal delivery of butyrate affects the provision of nutrients to the mammary gland. An alternative approach to achieve increased postruminal butyrate supply is to increase the synthesis of butyric acid in the GIT. Lactose, a substrate for butyric acid synthesis, has been shown to increase ruminal butyrate and circulating ketone concentrations in lactating dairy cows (DeFrain et al., 2004, 2006). Postruminal provision of butyric acid precursors to lactating dairy cows has not yet been evaluated.

Gluconic acid is a carboxylic acid naturally occurring in fruit and honey (Ramachandran et al., 2006). In non- 
ruminant animals, gluconic acid has been described as a butyric acid precursor (Asano et al., 1994, 2005; Tsukahara et al., 2002, 2006). Incubation of pig cecal digesta with gluconic acid in vitro resulted in greater apparent production of butyric acid, acetic acid, and lactic acid than incubations with glucose or sorbitol (Tsukahara et al., 2002). In isolates of this digesta, Lactobacillaceae, a family of lactic acid-producing bacteria, was identified as the predominant gluconic acid-utilizing bacteria, explaining the increased acetate and lactate production (Tsukahara et al., 2002, 2006). Butyrate synthesis was attributed to the presence of Megasphaera elsendii bacteria, which convert acetate and lactate to butyrate (Tsukahara et al., 2002, 2006). These findings are in agreement with Asano et al. (1994), who identified lactic acid-producing bacteria from the Bifidobacterium genus that proliferate in vitro by selectively utilizing gluconic acid. Together these findings suggest gluconic acid acts as a prebiotic in the GIT of nonruminant animals leading to increased VFA synthesis. A ruminant application has not yet been examined.

The objective of this experiment was to examine the effects of postruminal gluconic acid on fecal VFA concentrations, plasma metabolite concentrations [glucose, nonesterified fatty acid (NEFA), and BHB], and milk production in lactating dairy cows. As postruminal gluconic acid administration has not previously been evaluated, an efficacious dose has not been established. Therefore, this exploratory study evaluated different doses of gluconic acid, as calcium gluconate ( $\mathbf{C a G})$, delivered into the omasum. Only 1 study has previously examined $\mathrm{CaG}$ in ruminants; Emery et al. (1960) fed $57 \mathrm{~g} / \mathrm{d}$ of $\mathrm{CaG}$ in the TMR to herds in an uncontrolled field study. The doses selected in the present study were based on that of Emery et al. (1960) acknowledging that the availability and extent of utilization of $\mathrm{CaG}$ in the GIT of lactating ruminants is unknown. Given the proposed mode of action of gluconic acid as a butyric acid precursor, $\mathrm{NaB}$ was used in this study as a positive control. It was hypothesized that gluconic acid would elicit changes in fecal VFA profile, used as an indirect marker of fermentation patterns occurring in the lower GIT.

\section{MATERIALS AND METHODS}

The experiment was performed at the Trouw Nutrition Agresearch Dairy Facility (Burford, ON, Canada) from February to April, 2014. The Institutional Animal Care and Use Committee at Trouw Nutrition Agresearch Canada, in compliance with Canadian Council of Animal Care (1993) guidelines, approved all animal procedures.

\section{Animals and Feeding}

Six rumen-cannulated Holstein dairy cows (47.4 \pm $7.3 \mathrm{~kg} / \mathrm{d}$ of milk yield; $690 \pm 49 \mathrm{~kg}$ of BW) began the experiment at $60 \pm 6$ DIM. Animals were housed individually in tiestalls $\left(1.7 \mathrm{~m}^{2}\right)$ with pasture mats (Promat, Woodstock, ON, Canada) and chopped straw bedding and had free access to water via in-stall watering bowls. Cows were milked twice daily at 0500 and 1600 h. A TMR (Table 1) was offered once daily (0900 h) and formulated to meet energy, protein, vitamin, and mineral requirements of the animals as outlined by NRC (2001) [6.8 MJ/kg (1.63 Mcal $/ \mathrm{kg}$ of $\mathrm{NE}_{\mathrm{L}}, 15.5 \%$ CP, DM basis)]. Cows were fed ad libitum for a 14-d acclimation period before the start of the experiment. The DMI was fixed for individual cows during the experiment using the average intake of the last $7 \mathrm{~d}$ of the acclimation period and was measured daily throughout the experiment. Samples of the TMR were taken weekly and stored at $-20^{\circ} \mathrm{C}$ pending nutrient analysis. Forages were monitored weekly for DM content and the TMR offering was adjusted accordingly.

\section{Study Design}

The experiment was designed as a $6 \times 6$ Latin square with 6 experimental periods, where 6 cows were randomly assigned 1 of 6 treatment sequences. Treat-

Table 1. Ingredient and chemical composition of the TMR (\% of DM, unless otherwise indicated)

\begin{tabular}{lc}
\hline Item & Content \\
\hline Ingredient & \\
Corn silage & 30.6 \\
Alfalfa silage & 27.7 \\
Mixed hay & 5.4 \\
Dairy supplement ${ }^{1}$ & 36.3 \\
Nutrient & \\
DM, \% & 50.5 \\
NE, MJ $/ \mathrm{kg}$ of DM (Mcal/kg of DM) & $6.8(1.6)$ \\
CP & 16.2 \\
Total fat & 3.6 \\
NDF & 33.6 \\
ADF & 24.0 \\
Ash & 8.7 \\
Ca & 0.8 \\
P & 0.4 \\
Vitamin A, IU $/ \mathrm{kg}$ & 4,890 \\
Vitamin D, IU/kg & 1,333 \\
Vitamin E, IU/kg & 36 \\
\hline
\end{tabular}

${ }^{1}$ Manufactured by Shur-Gain (St. Mary's, ON, Canada) and consisted (\% of DM) of ground corn (30.8), fine rolled corn (20.6), Topsoy formaldehyde-treated soybean meal (10.3), soybean meal (6.4), barley (5.5), beet pulp (5.1), wheat shorts (5.2), soyhulls (5.1), palm fat (2.7), pork meal (2.1), sodium chloride (1.3), feather meal (1.3), sodium sesquicarbonate (1.2), calcium carbonate (0.7), urea (0.6), magnesium oxide (0.5), vitamin and mineral premix (0.4), selenium (0.1), BioPower live yeast (0.1), Rumensin (0.02), and corn gluten meal (0.01). 
ment arrangement in the Latin square was balanced for carryover and uniform within period and sequence (Williams, 1949). Treatments were prepared daily and included a negative control of saline $(\mathbf{C O N}, 0.90 \%$ $\mathrm{NaCl}$ wt/vol), a positive control of $\mathrm{NaB}(135 \mathrm{~g} / \mathrm{d})$, and 4 doses of $\mathrm{CaG}(44,93,140$, or $187 \mathrm{~g} / \mathrm{d})$. The $\mathrm{NaB}$ solution was $135 \mathrm{~g}$ of Na-butyrate (Sigma-Aldrich Corporation, St. Louis, MO) dissolved in $6 \mathrm{~L}$ of water. Calcium gluconate treatments were prepared by dissolving 44, 93, 140, or $187 \mathrm{~g}$ of $\mathrm{CaG}$ (Sciencelab.com Inc., Dickinson, TX) in $6 \mathrm{~L}$ of water. All treatments were administered via an infusion line placed $1 \mathrm{~d}$ before study. The infusion technique was adapted from Gressley et al. (2006). The infusion line was made of flexible polyvinyl chloride tubing $(0.32 \mathrm{~cm}$ inner diameter, 0.64 $\mathrm{cm}$ outer diameter, Fisher Scientific, Toronto, Canada) and was passed through a hole in the rumen cannula plug (10 cm center diameter cannula, \#1C 4", Bar Diamond, Parma, ID). The other end passed through a hole in a Plastisol flange $(15 \mathrm{~mm}$ diameter, $5 \mathrm{~mm}$ height) that had 5 holes $(1.5 \mathrm{~cm}$ diameter) to aid in the passage of digesta. The flange was folded in the hand and then released after passing the sulcus omasi, thereby securing the infusion line in the abomasum. Placement of the infusion line in the abomasum was checked daily. As this technique does not ensure line placement in the abomasum at all times, reference to postruminal infusion has been used. Test treatments were infused $(6 \mathrm{~L} / \mathrm{d})$ continuously for $5 \mathrm{~d}$ at a rate of $4.17 \mathrm{~mL} / \mathrm{min}$ via a Watson-Marlow 205U/CA multichannel peristaltic pump (Wilmington, MA). The 5-d infusion period was followed by a 2 -d wash-out period between each infusion period.

On the final day of each infusion period (d 5), samples of milk, feces, and blood were collected from each animal. Milk was collected, weighed, and sampled separately at the morning and evening milkings, then stored at $4^{\circ} \mathrm{C}$ for analysis within $3 \mathrm{~d}$. Fresh feces were collected from the rectum of the animal, then stored and shipped on ice for analysis on the same day as collection. Blood samples were collected from the coccygeal vessels into $10 \mathrm{~mL}$ of sodium heparin and potassium EDTA Vacutainers (Becton Dickinson, Rutherford, NJ) at 4 time points $(0800,1000,1200$, and $1400 \mathrm{~h})$. Collection tubes were immediately placed on ice and centrifuged at $1,500 \times g$ for 15 min at room temperature. Plasma was pooled over sampling time points by cow within period and stored at $-20^{\circ} \mathrm{C}$ until analysis.

\section{Biochemical Analyses}

Proximate composition of the forage samples was determined by near-infrared spectroscopy (Nutreco Cana- da Inc., St. Hyacinthe, QC, Canada). Milk was analyzed for protein and lactose by infrared spectroscopy and fat by Fourier-transform mid-infrared spectroscopy (Animal Health Laboratory, University of Guelph, Guelph, ON, Canada). Fecal VFA were determined by HPLC (Actlabs, Ancaster, ON, Canada). Spectrophotometric assays were used to analyze glucose (Sigma kit no. 510A; Raabo and Terkildsen, 1960), NEFA (NEFA C kit; Wako Chemicals GmbH, Neuss, Germany; Johnson and Peters, 1993), and BHB (Cant et al., 1993).

\section{Calculations and Statistical Analysis}

Energy-corrected milk yield was calculated as [ 0.3246 $\times \mathrm{kg}$ of milk $)+(12.86 \times \mathrm{kg}$ of fat $)+(7.04 \times \mathrm{kg}$ of protein] (derived from Tyrrell and Reid, 1965). All data were analyzed in SAS studio (SAS 9.4M5, SAS Institute Inc., Cary, NC). Data were modeled in the GLIMMIX procedure of SAS with treatment and period as fixed effects and cow as a random effect. Orthogonal polynomial contrast coefficients were generated using the IML procedure of SAS, using $\mathrm{CaG}$ doses of 0,44 , 93, 140, and $187 \mathrm{~g} / \mathrm{d}$ with $4 \mathrm{df}$ to examine for linear and quadratic dose relationships. Contrasts were used to examine the effect of all CaG treatments versus CON and versus $\mathrm{NaB}$. The conditional studentized residuals were checked for normality for all models. Treatment effects were declared at $P \leq 0.05$ and tendencies for treatment effects at $0.05<P \leq 0.10$. All data are expressed as least squares means and standard errors of the means.

\section{RESULTS}

\section{Fecal Volatile Fatty Acids}

Fecal VFA concentrations are reported in Table 2. Infusion of $\mathrm{CaG}$ did not affect fecal concentration of acetic acid, propionic acid, butyric acid, valeric acid, or iso-valeric acid. Calcium gluconate infusion increased iso-butyric acid concentration compared with CON $(P$ $=0.03)$ and the dose relationship was quadratic $(P=$ 0.01 ). No differences were observed in fecal VFA concentrations between infusions of $\mathrm{CaG}$ or $\mathrm{NaB}$.

\section{Blood Metabolites}

Arterial plasma metabolite concentrations are presented in Table 3. Calcium gluconate infusion decreased plasma glucose compared with $\mathrm{CON}(P=0.01)$, displaying a linear relationship $(P=0.02)$. Calcium gluconate infusion decreased plasma NEFA concentrations compared with $\operatorname{CON}(P=0.03)$, which tended to display a linear relationship $(P=0.07)$. Plasma BHB 
Table 2. Volatile fatty acid concentration $(\mu \mathrm{mol} / \mathrm{g})$ in feces of lactating dairy cows $(\mathrm{n}=6)$ receiving an omasal infusion of saline $(\mathrm{CON})$, sodium butyrate $(\mathrm{NaB}, 135 \mathrm{~g} / \mathrm{d})$, or $44,93,140,187 \mathrm{~g} / \mathrm{d}$ of calcium gluconate $(\mathrm{CaG})^{1}$

\begin{tabular}{|c|c|c|c|c|c|c|c|c|c|c|c|}
\hline \multirow[b]{2}{*}{ Item } & \multirow[b]{2}{*}{$\mathrm{CON}$} & \multirow[b]{2}{*}{$\mathrm{NaB}$} & \multicolumn{4}{|c|}{$\mathrm{CaG}, \mathrm{g} / \mathrm{d}$} & \multirow[b]{2}{*}{ SEM } & \multicolumn{4}{|c|}{ Contrast $^{2}$} \\
\hline & & & 44 & 93 & 140 & 187 & & $\mathrm{CON}$ vs. $\mathrm{CaG}$ & $\mathrm{NaB}$ vs. $\mathrm{CaG}$ & $\mathrm{L}$ & Q \\
\hline Propionic acid & 64.8 & 74.5 & 93.6 & 79.1 & 66.8 & 70.2 & 9.5 & 0.24 & 0.78 & 0.57 & 0.20 \\
\hline Butyric acid & 41.2 & 37.5 & 43.9 & 39.1 & 30.3 & 42.0 & 4.2 & 0.65 & 0.72 & 0.40 & 0.39 \\
\hline Isobutyric acid & 9.7 & 11.4 & 13.3 & 11.6 & 11.7 & 10.3 & 0.9 & 0.03 & 0.70 & 0.84 & 0.01 \\
\hline Valeric acid & 14.4 & 15.8 & 14.6 & 15.2 & 15.6 & 14.0 & 0.7 & 0.58 & 0.25 & 0.93 & 0.16 \\
\hline
\end{tabular}

${ }^{1}$ Data expressed as LSM.

${ }^{2} P$-values for $\mathrm{L}=$ linear, $\mathrm{Q}=$ quadratic.

concentration was significantly increased with $\mathrm{CaG}$ infusion $(P=0.01)$ and displayed a quadratic relationship $(P=0.02)$. No difference was observed in plasma glucose concentrations between infusions of $\mathrm{CaG}$ or $\mathrm{NaB}$. Concentrations of plasma NEFA were lower with CaG infusion compared with $\mathrm{NaB}(P=0.02)$, whereas plasma $\mathrm{BHB}$ concentrations were greater with $\mathrm{CaG}$ infusion compared with $\mathrm{NaB}(P=0.03)$.

\section{Feed Intake and Milk Production and Composition}

Dry matter intake and milk production parameters are presented in Table 4. Infusion of CaG did not affect milk yield, lactose and protein yield, and lactose concentration. Quadratic responses for DMI $(P=0.04)$ and milk protein concentration $(P=0.02)$ were observed; however, no relationships between all $\mathrm{CaG}$ treatments and $\mathrm{CON}$ were noted. Milk fat concentration increased in response to $\mathrm{CaG}$ infusion compared with $\mathrm{CON}(P=$ $0.02)$; however, the dose relationship was not described by linear $(P=0.08)$ or quadratic responses $(P=0.83)$. Infusion of $\mathrm{CaG}$ tended to increase milk fat yield $(P$ $=0.08$ ), with the $44 \mathrm{~g} / \mathrm{d}$ dose resulting in the highest numerical milk fat yield. Yield of ECM tended to increase with $\mathrm{CaG}$ infusion $(P=0.08)$. No differences were observed between infusions of $\mathrm{CaG}$ or $\mathrm{NaB}$, with the exception of a tendency for protein concentration to decrease with $\mathrm{CaG}$ infusion $(P=0.06)$.

\section{DISCUSSION}

This study examined the use of $\mathrm{CaG}$ as a strategy for increasing butyric acid production in the GIT of lactating dairy cows. Fecal concentration of iso-butyric acid increased when $\mathrm{CaG}$ was infused postruminally. This finding is in agreement with our hypothesis that $\mathrm{CaG}$ would alter fermentation patterns in the GIT of lactating dairy cows, and with Asano et al. (1994) who observed alterations in bacterial populations in the feces of humans consuming 3 and $9 \mathrm{~g} / \mathrm{d}$ of gluconate. Fecal measurement provide an indirect marker of fermentation occurring in the lower GIT. The notion that gluconic acid was used in the lower gut is supported by studies in nonruminant animals. Asano et al. (1994) demonstrated in a rat model that approximately $20 \%$ of ingested gluconic acid is absorbed in the small intestine, suggesting that the majority reaches the large intestine. Further, gluconic acid increased the apparent production of acetate, lactate, and butyrate in cultured cecal digesta of pigs (Tsukahara et al., 2002). It was also determined that VFA production in porcine cecal digesta was stimulated by the metabolic interactions between lactic acid-producing bacteria, Lactobacillus acidophilus, and lactic acid-utilizing bacteria, Megasphera elsdenii (Tsukahara et al., 2006). Fecal measurements taken in the present study provided a noninvasive method to assess changes in fermentation patterns occurring in

Table 3. Arterial plasma metabolite concentrations $(\mathrm{mmol} / \mathrm{L})$ of lactating dairy cows $(\mathrm{n}=6)$ receiving an omasal infusion of saline $(\mathrm{CON})$, sodium butyrate $(\mathrm{NaB}, 135 \mathrm{~g} / \mathrm{d})$, or $44,93,140$, and $187 \mathrm{~g} / \mathrm{d}$ of calcium gluconate $(\mathrm{CaG})^{1}$

\begin{tabular}{|c|c|c|c|c|c|c|c|c|c|c|c|}
\hline Item & $\mathrm{CON}$ & $\mathrm{NaB}$ & \multicolumn{4}{|c|}{$\mathrm{CaG}, \mathrm{g} / \mathrm{d}$} & SEM & \multicolumn{4}{|c|}{ Contrast $^{2}$} \\
\hline Glucose & 3.29 & 2.87 & 3.05 & 2.98 & 3.08 & 2.96 & 0.12 & 0.01 & 0.12 & 0.02 & 0.19 \\
\hline $\mathrm{BHB}$ & 0.812 & 0.972 & 1.703 & 1.090 & 1.359 & 1.120 & 0.199 & 0.01 & 0.03 & 0.58 & 0.02 \\
\hline
\end{tabular}

\footnotetext{
${ }^{1}$ Data expressed as LSM.

${ }^{2} P$-values for $\mathrm{L}=$ linear, $\mathrm{Q}=$ quadratic.

${ }^{3} \mathrm{NEFA}=$ nonesterified fatty acids.
} 
the lower GIT. However, quantification of the bacterial species present would provide a more sensitive analysis of GIT dynamics. Alternatively, CaG may be converted to butyrate and absorbed in other regions of the GIT of dairy cattle, including the reticulum-omasum. Indeed, the infusion technique used in this study could not guarantee that the infusion line remained in the abomasum at all times. Direct sampling of the GIT contents was a methodological constraint in the current model. Such methodology would be useful to understand the mode of action of $\mathrm{CaG}$, particularly in light of our finding that only iso-butyrate increased in feces.

Calcium gluconate administration appeared to alter the provision of energy substrates available to the mammary gland. Specifically, arterial glucose and NEFA concentrations were decreased and BHB concentration was increased in arterial plasma supply compared with CON. Glucose concentrations were also numerically lowest with $\mathrm{NaB}$ infusion, but no difference was detected between $\mathrm{CaG}$ and $\mathrm{NaB}$. Decreased plasma glucose in response to butyrate supplementation is consistent with other studies (Neogrady et al., 1989; Huhtanen et al., 1993; Herrick et al., 2018), although the mechanism is not fully understood. In nonruminants, evidence indicates that butyrate has a regulatory role in glucose and lipid metabolic pathways in multiple tissues (reviewed by McNabney and Henagan, 2017). Similarly, glucose synthesis from propionate was inhibited by butyrate in sheep hepatocytes (Demigne et al., 1986; Aiello et al., 1989). Concomitant with reductions in circulating glucose, increases in venous BHB concentrations have been observed in response to increased rumen butyrate supply (Huhtanen et al., 1993; Miettinen and Huhtanen, 1996). Similarly, postruminal delivery of butyrate (0.7 and $1.4 \mathrm{~kg} / \mathrm{d}$ ) also increased venous BHB concentrations in lactating dairy cows (Herrick et al., 2018). Arterial BHB concentrations in response to all doses of $\mathrm{CaG}$ infusion were numerically greater than that of CON and NaB. Like Herrick et al. (2018), these concentrations exceed the proposed threshold for healthy cows (>1 mmol/L; Duffield et al., 1998). However, normal plasma glucose and NEFA concentrations were maintained despite their changes in response to $\mathrm{CaG}$, and cows showed no symptoms of metabolic disorder during the study. Elevated plasma BHB in response to $\mathrm{CaG}$ infusion may have been attributed, in part, to ketogenesis in the GIT. However, this hypothesis remains to be tested. It is worth noting that the duration of the infusion period ( $5 \mathrm{~d}$ ) may have too short to elicit clinical symptoms of metabolic dysfunction.

Postruminal CaG increased milk fat concentration and yield and resulted in greater yield of ECM than CON. No production parameters differed between $\mathrm{NaB}$ and CaG. The same basal diet was fed to all animals. Dry matter intake was fixed before study initiation; however, a quadratic response in DMI to CaG administration was observed. Changes in milk components were related to the delivery of $\mathrm{CaG}$ to the GIT and the effects of its metabolism by and absorption across the GIT. The relationship between yield of milk fat and ECM and CaG dose were not described by linear or quadratic trends. The number of doses chosen and the inclusion of a negative and positive control represent the practical and economic limits of conducting intensive exploratory methodology. Repetition of this work with a greater number of replicates and number of doses is warranted. Future studies should also increase the duration of experimental periods to ensure adequate adaptation to the $\mathrm{CaG}$ treatment. Postruminal delivery of $\mathrm{CaG}$ in the present study was modeled after its GIT application in nonruminants. To our knowledge, only 1 study has administered $\mathrm{CaG}$ in feed to ruminants. Emery et al. (1960) conducted a field study and observed an increase in milk fat percentage $(+0.06 \%)$ and FCM

Table 4. Dry matter intake, milk yield, and milk component yield and composition of lactating dairy cows $(\mathrm{n}=6)$ receiving an omasal infusion of saline $(\mathrm{CON})$, sodium butyrate $(\mathrm{NaB}, 135 \mathrm{~g} / \mathrm{d})$, or $44,93,140$, and $187 \mathrm{~g} / \mathrm{d}$ of calcium gluconate $(\mathrm{CaG})^{1}$

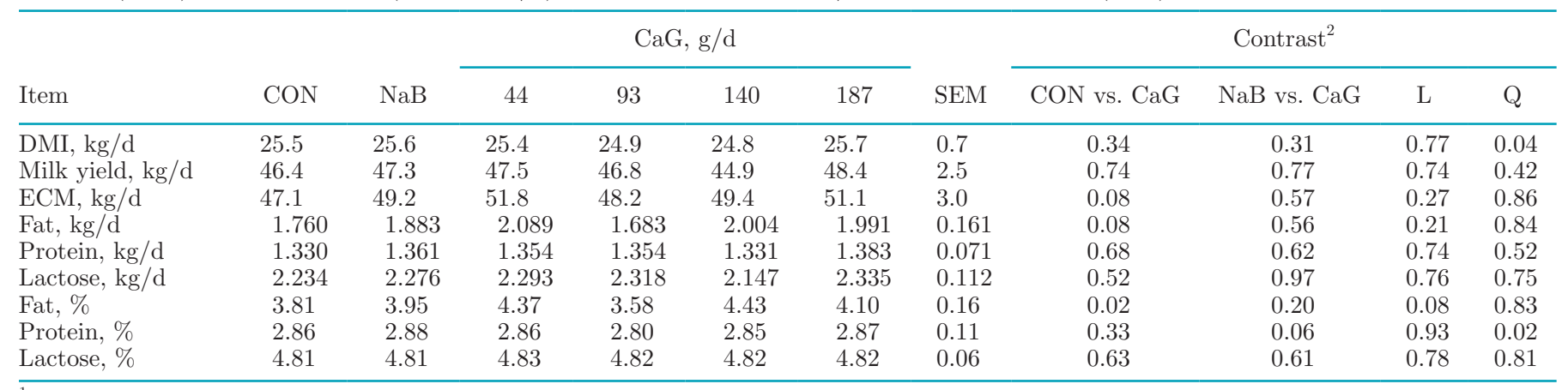

${ }^{1}$ Data expressed as LSM from the final day of each period.

${ }^{2} P$-values for $\mathrm{L}=$ linear, $\mathrm{Q}=$ quadratic. 
yield $(+771 \mathrm{~g} / \mathrm{d})$ in herds fed $57 \mathrm{~g} / \mathrm{d}$ of $\mathrm{CaG}$ in the TMR. The results of this field study are difficult to interpret because DMI, dietary ingredients, and details of the statistical analysis were not reported. Regardless, the similar responses in milk fat production between studies are favorable toward a postrumen application of $\mathrm{CaG}$ and require further investigation in controlled experiments. Indeed, milk production responses in lactating dairy cattle to ruminal butyrate supplementation have also noted increased fat yield and ketone concentration of milk (Huhtanen et al., 1993), as well as increased short-chain fatty acid concentrations in milk (Miettinen and Huhtanen, 1996). Herrick et al. (2018) infused butyrate postruminally and reported no change in milk fat yield but increased short-chain fatty acid and decreased long-chain fatty acid concentrations in milk. Milk fatty acid composition was not analyzed in the present study, but should be investigated in future experiments.

\section{CONCLUSIONS}

This study was an exploratory evaluation of postruminal $\mathrm{CaG}$ administration in lactating dairy cows. Calcium gluconate infusion increased concentration of fecal iso-butyric acid, used in this study as an indirect marker of lower GIT fermentation. Arterial plasma concentrations of NEFA and BHB increased and glucose decreased with $\mathrm{CaG}$ infusion. These metabolic changes were accompanied by increased milk fat yield and concentration as well as increased ECM. Improved milk production parameters observed with $\mathrm{CaG}$ infusion were not described by linear or quadratic dose relationships. Together these findings suggest that $\mathrm{CaG}$ alters the provision of nutrients to the mammary glands leading to increased milk fat production; a response likely orchestrated by multiple metabolic systems. A limitation of the current work is small sample size. Further evaluation of $\mathrm{CaG}$ using a larger number of animals is warranted. In addition, a more comprehensive examination of the mode of action of $\mathrm{CaG}$ in lactating animals is necessary to understand the complex dose relationships observed. Further work is also need to establish the site of $\mathrm{CaG}$ utilization within the GIT. The technique employed in this present study could not guarantee that the infusion line remained in the abomasum at all times.

\section{ACKNOWLEDGMENTS}

This research was funded by Trouw Nutrition. J. Doelman, L. McKnight, M. Carson, D. Waterman, and J. Metcalf are employees of Trouw Nutrition. We acknowledge the efforts of Angela Woo of the Trouw Nutrition Agresearch laboratory in Guelph for assistance with the infusion lines, raw materials, and analyses. Thank you to the staff of the Trouw Nutrition Agresearch Dairy Facility for the care of the animals and assisting with animal procedures.

\section{REFERENCES}

Aiello, R. J., L. E. Armentano, S. J. Bertics, and A. T. Murphy. 1989. Volatile fatty acid uptake and propionate metabolism in ruminant hepatocytes. J. Dairy Sci. 72:942-949.

Asano, T., K. Yuasa, K. Kunugita, T. Teraji, and T. Mitsuoka. 1994. Effects of gluconic acid on human fecal bacteria. Microb. Ecol. Health Dis. 7:247-256.

Asano, T., K. Yuasa, S. Nishiwaki, and H. Lino. 2005. Isolation rates of gluconate-fermenting bifidobacteria from human feces. Microb. Ecol. Health Dis. 7:247-256.

Bergman, E. N. 1990. Energy contributions of volatile fatty acids from the gastrointestinal tract in various species. Physiol. Rev. 70:567590. https://doi.org/10.1152/physrev.1990.70.2.567.

Canadian Council on Animal Care. 1993. Guide to the Care and Use of Experimental Animals. Vol. 1. E. D. Offert, B. M. Cross, and A. A. McWilliam, ed. CCAC, Ottawa, Ontario, Canada.

Cant, J. P., E. J. DePeters, and R. L. Baldwin. 1993. Mammary uptake of energy metabolites in dairy cows fed fat and its relationship to milk protein depression. J. Dairy Sci. 76:2254-2265.

DeFrain, J. M., A. R. Hippen, K. F. Kalscheur, and D. J. Schingoethe. 2004. Feeding lactose increases ruminal butyrate and plasma $\beta$-hydroxybutyrate in lactating dairy cows. J. Dairy Sci. 87:24862494. https://doi.org/10.3168/jds.S0022-0302(04)73373-1.

DeFrain, J. M., A. R. Hippen, K. F. Kalscheur, and D. J. Schingoethe. 2006. Feeding lactose to increase ruminal butyrate and the metabolic status of transition dairy cows. J. Dairy Sci. 89:267-276. https://doi.org/10.3168/jds.S0022-0302(06)72091-4.

Demigne, C., C. Yacoub, C. Remesy, and P. Fafournoux. 1986. Propionate and butyrate metabolism in rat or sheep hepatocytes. Biochim. Biophys. Acta 875:535-542.

Duffield, T. F., D. Sandals, K. E. Leslie, K. Lissemore, B. W. McBride, J. H. Lumsden, P. Dick, and R. Bagg. 1998. Efficacy of monensin for the prevention of subclinical ketosis in lactating dairy cows. J. Dairy Sci. 81:2866-2873. https://doi.org/10.3168/jds.S0022 -0302(98)75846-1.

Emery, R. S., C. K. Smith, T. R. Lewis, J. DeHate, and L. D. Brown. 1960. Effect of a modified sulfite waste liquor and of calcium gluconate on milk production. J. Dairy Sci. 43:1643-1647.

Gressley, T. F., S. M. Reynal, J. J. Olmos Colmenero, G. A. Broderick, and L. E. Armentano. 2006. Technical Note: Development of a tool to insert abomasal infusion lines into dairy cows. J. Dairy Sci. 89:3965-3967.

Herrick, K. J., A. R. Hippen, K. F. Kalscheur, D. J. Schingoethe, D. P. Casper, S. C. Moreland, and J. E. van Eys. 2017. Singledose infusion of sodium butyrate, but not lactose, increases plasma $\beta$-hydroxybutyrate and insulin in lactating dairy cows. J. Dairy Sci. 100:757-768

Herrick, K. J., A. R. Hippen, K. F. Kalscheur, D. J. Schingoethe, S. D. Ranathunga, J. L. Anderson, S. C. Moreland, and J. E. van Eys. 2018. Infusion of butyrate affects plasma glucose, butyrate, and $\beta$-hydroxybutyrate but not plasma insulin in lactating dairy cows. J. Dairy Sci. 101:3524-3536.

Huhtanen, P., H. Miettinen, and M. Ylinen. 1993. Effect of increasing ruminal butyrate on milk yield and blood constituents in dairy cows fed a grass silage-based diet. J. Dairy Sci. 76:1114-1124. https://doi.org/10.3168/jds.S0022-0302(93)77440-8.

Johnson, M. M., and J. P. Peters. 1993. Technical note: An improved method to quantify nonesterified fatty acids in bovine plasma. J. Anim. Sci. 71:753-756. 
McNabney, S. M., and T. M. Henagan. 2017. Short chain fatty acids in the colon and peripheral tissues: A focus on butyrate, colon cancer, obesity and insulin resistance. Nutrients 9:1348-1376. https://doi .org/10.3390/nu9121348.

Miettinen, H., and P. Huhtanen. 1996. Effects of the ratio of ruminal propionate to butyrate on milk yield and blood metabolites in dairy cows. J. Dairy Sci. 79:851-861. https://doi.org/10.3168/jds .S0022-0302(96)76434-2.

Neogrady, Z., P. Galfi, and F. Kutas. 1989. Effect of intraruminal butyrate infusion on the plasma insulin level in sheep. Acta Vet. Hung. 37:247-253.

NRC. 2001. Nutrient Requirements of Dairy Cattle. 7th rev. ed. Natl. Acad. Sci., Washington, DC.

Penner, G. B., M. A. Steele, J. R. Aschenbach, and B. W. McBride. 2011. Ruminant Nutrition Symposium: Molecular adaptation of ruminal epithelia to highly fermentable diets. J. Anim. Sci. 89:1108-1119. https://doi.org/10.2527/jas.2010-3378.

Raabo, E., and T. C. Terkildsen. 1960. On the enzymatic determination of blood glucose. Scand. J. Clin. Lab. Invest. 12:402-407.
Ramachandran, S., P. Fontanille, A. Pandey, and C. Larroche. 2006. Gluconic acid: Properties, applications and microbial production. Food Technol. Biotechnol. 44:185-195.

Tsukahara, T., K. Hashizume, H. Koyama, and K. Ushida. 2006. Stimulation of butyrate production through the metabolic interaction among lactic acid bacteria, Lactobacillus acidophilus, and lactic acid-utilizing bacteria, Megasphaera elsdenii, in porcine cecal digesta. J. Anim. Sci. 77:454-461. https://doi.org/10.1111/j.1740 $-0929.2006 .00372$

Tsukahara, T., K. Koyama, M. Okada, and K. Ushida. 2002. Stimulation of butyrate production by gluconic acid in pig cecal digesta and identification of butyrate producing bacteria. J. Nutr. 132:2229-2234

Tyrrell, H. F., and J. T. Reid. 1965. Prediction of the energy value of cow's milk. J. Dairy Sci. 48:1215-1223. https://doi.org/10.3168/ jds.S0022-0302(65)88430-2.

Williams, E. J. 1949. Experimental designs balanced for the estimation of residual effects of treatments. Aust. J. Sci. Res. A 2:149-168. 